\title{
Multiple chromosomal and phenotypic changes in spontaneous mutants of Candida albicans
}

\author{
Elena P. Rustchenko-Bulgac ${ }^{1 *}$ and Dexter H. Howard ${ }^{2}$ \\ ${ }^{1}$ Department of Biochemistry, University of Rochester, School of Medicine and Dentistry, Rochester, \\ New York 14642, USA \\ ${ }^{2}$ Department of Microbiology and Immunology, UCLA School of Medicine, University of California, Los Angeles, \\ California 90024, USA
}

(Received 25 August 1992; revised 22 January 1993; accepted 2 February 1993)

\begin{abstract}
Previous studies have revealed the occurrence of multiple chromosomal alterations among spontaneous colony form mutants and clinical isolates of Candida albicans. In this report we show that such karyotype alterations are also seen in spontaneous and induced non-germinative mutants of the fungus. To determine if phenotypic changes other than colony form and microscopic morphology accompanied the rearrangements of the electrophoretic karyotype, we studied the following characteristics of the non-germinative and some of the colony form mutants: formation of pseudohyphae, chlamydospore production, germ tube formation, colony morphology, auxotrophy, growth at various temperatures, and colony morphology and pigment formation on selected media (bismuth sulphite and Phloxine B). We established that phenotypic and karyotypic variability among spontaneous, non-germinative mutants was no different than such variability among spontaneous colony form mutants. Thus, non-germination may represent another phenotypic consequence of genomic instability in $C$. albicans. The variability in different phenotypic attributes that occurred amongst the mutants was not associated with any given karyotype. Moreover, neither the low nor the high phenotypic variabilities observed were explained by the relatively high number of alterations in a limited number of chromosomes.
\end{abstract}

\section{Introduction}

The electrophoretic karyotype of clinical isolates of Candida albicans is highly variable (Merz et al., 1988). Initially, such variation was considered to offer reasonable grounds for establishing strain differences that might be used in epidemiological work (Merz, 1990). However, it has become clear that single strains, either fresh isolates or stock cultures, may give rise to mutants with single and multiple alterations in their electrophoretic karyotypes and that the frequency of such spontaneous mutations may be high (Suzuki et al., 1989; Rustchenko-Bulgac et al., 1990; Rustchenko-Bulgac, 1991).

The phenotypes so far associated with multiple chromosomal aberrations in $C$. albicans are morpho-

\footnotetext{
*Author for correspondence.
}

Abbreviations: BiGGY agar, bismuth sulphite glucose glycine yeast agar; GPA, glucose peptone agar; LBC medium, Lee, Buckley and Campbell medium; YPD agar, yeast extract peptone dextrose agar. logical mutants with changes in colony form, microscopic morphology and growth rate (Rustchenko-Bulgac et al., 1990; Rustchenko-Bulgac, 1991), and germinationdeficient mutants (Dabrowa et al., 1990 b). Changes in the growth rate as well as sucrose assimilation accompanying chromosome alterations were also reported in C. stellatoidea (Wickes et al., 1991). Previously we reviewed briefly the literature on different phenotypic changes in spontaneous colony morphology mutants of C. albicans (Rustchenko-Bulgac et al., 1990) which, one might assume because of recent work (RustchenkoBulgac, 1991), probably had altered electrophoretic karyotypes. No systematic study, however, was done to analyse this presumed connection. We therefore set about to determine if phenotypic alterations regularly accompanied chromosomal variability in non-germinative and colony form mutants of $C$. albicans. The phenotypic characters studied included chlamydospore production, pseudohyphal formations, germ tube formation, colony morphology, auxotrophy, growth at various temperatures, colony morphology and pigment formation on selected media. 
We observed that the phenotypic variability of individual characters was either very high or very low but that neither high nor low levels of variability corresponded to the level of karyotypic variability. Additionally, no specific pattern of chromosomal alterations was observed which could be associated with any level of phenotypic variability studied. It would appear that some attributes other than those studied, perhaps those more allied to the commensal or potentially pathogenic existence of the opportunistic, zoopathogenic fungus will be found to be more closely related to chromosomal rearrangements of $C$. albicans.

\section{Methods}

Strains of C. albicans. The origins of the parental strains, the colony form mutants, and the non-germinative mutants studied are given in Table 1. There are two groups of germination-deficient mutants: those that arise spontaneously (A) and those that are derived after mutagenesis with NTG or UV-irradiation (B). A group of germinationcompetent mutants (group C, Table 1) consisted of the clinical isolate $3153 \mathrm{~A}$ and its spontaneous morphological mutants $\mathrm{ml}-\mathrm{m} 20$ (Rustchenko-Bulgac et al., 1990; Rustchenko-Bulgac, 1991).

Isolation of spontaneous non-germinative mutants. Strains 301, 302 and 303 (see Table 1 for original designations) were spontaneous mutants of strain 300 plated on glucose peptone agar (GPA; Buckley et al., 1982). The strain 300-SG was a spontaneous mutant observed because of its small colony size among customary-sized colonies of strain 300 streaked on GPA and incubated at room temperature for $48 \mathrm{~h}$ (Howard et al., 1986).

Isolation of induced non-germinative mutants. The NTG mutagenesis was performed by a method described previously (Howard \& Dabrowa, 1979). Briefly, $1 \times 10^{7}$ yeast cells of strain 307 were suspended in $4 \mathrm{ml}$ $0 \cdot 1$ M-citrate buffer at pH $5 \cdot 5$ (citric acid, $10.5 \mathrm{~g} ; \mathrm{NaOH}, 4.4 \mathrm{~g}$, made up to $500 \mathrm{ml}$ and adjusted to $\mathrm{pH} 5 \cdot 5$ with $2 \mathrm{M}-\mathrm{NaOH}$ ) and exposed to $50 \mathrm{mg} \mathrm{NTG} \mathrm{(} \mathrm{ml}$ buffer $)^{-1}$. The yeast cells were shaken at $37^{\circ} \mathrm{C}$ for $85 \mathrm{~min}$; mutagenesis was stopped by passing the suspensions through a Millipore filter and washing the pads several times with distilled water. Mutants were enriched and selected by a germination-filtration method (Cannon, 1986; Howard \& Dabrowa, 1979).

The methods used to generate the UV-induced non-germinative mutants have not been published (Table 1). However, the method of UV-irradiation used by the same group in other studies was a standard one (Oblack et al., 1980). Briefly, distilled-water-suspended yeast cells $\left(5 \times 10^{6} \mathrm{ml}^{-1}\right)$ of strain 310 contained in an open Petri dish were exposed to a $15 \mathrm{~W}$ germicidal lamp (General Electric; $5 \cdot 1 \times 10^{-9} \mathrm{~J} \mathrm{~m}^{-2}$ output at a distance of $40 \mathrm{~cm}$ ) for $7 \mathrm{~min}$ at room temperature (Oblack et al., 1980).

Isolation of colony form mutants. The colony form mutants arose spontaneously from strain 3153A (Rustchenko-Bulgac et al., 1990) at a frequency of about $1 \cdot 4 \%$.

Reference strains. Previously analysed strains WO-1 and 3153A of $C$. albicans (Rustchenko-Bulgac et al., 1990; Rustchenko-Bulgac, 1991) served as references for the positions of bands in electrophoretic karyotypes.

Establishing that the non-germinative mutants were related to the indicated parent by hybridization analyses with specific probe $\mathrm{Ca} 3$. Southern blot hybridization of total cellular DNA from the mutants and their parental strains with the $C$. albicans-specific mid-repeat sequence Ca3 (Sadhu et al., 1991) was performed. Genomic DNA was digested with $E c o$ RI (New England Biolabs). Fragments were separated on a $0.7 \%$ agarose gel and transferred to GeneScreen Plus (Dupont, NEN Research Products). Southern blot hybridization with nicktranslated $\mathrm{Ca} 3$ was performed according to general protocols.

Maintenance and growth of strains. Because of instabilities of the strains, the special method of maintenance $\left(-70^{\circ} \mathrm{C}\right)$ and growth of strains was used in these studies (Rustchenko-Bulgac, 1991). The recipes for yeast extract peptone dextrose (YPD) medium, GPA and Lee-Buckley-Campbell (LBC) synthetic medium have been published (Sherman et al., 1986; Howard et al., 1986). Bismuth sulphite glucose glycine yeast (BiGGY) agar was prepared in accordance with the manufacturer's instructions (Difco). Phloxine B medium was made by adding $5 \mathrm{mg}$ Phloxine B ( $\mathrm{ml}$ LBC agar $)^{-1}$.

Chlamydospore formation. Chlamydospore formation was determined at room temperature on corn meal agar (Difco) supplemented with $1 \%(\mathrm{v} / \mathrm{v})$ Tween- 80 . The tests were performed in accordance with standard procedures (Cooper \& Silva-Hutner, 1985). Determination of the ability to form pseudohyphae was made on the same medium.

Germ tube formation. The strains to be tested for germ tube formation were grown on GPA at room temperature for $24 \mathrm{~h}$. The cells were harvested, washed in distilled water and inoculated (about $10^{6}$ cells $\mathrm{ml}^{-1}$ ) into $0.5 \mathrm{ml}$ prewarmed calf serum (HyClone Laboratories) and incubated at $37^{\circ} \mathrm{C}$ for $3 \mathrm{~h}$. The percentage of cells with germ tubes was determined microscopically at the end of the incubation period.

Standard conditions for examining colonial morphologies. The protocol for studying individual colonial morphology was described previously (Rustchenko-Bulgac et al., 1990; Rustchenko-Bulgac, 1991).

Growth on BiGGY agar and Phloxine B agar. Strains were plated for individual colonies (10-20 per plate) on BiGGY agar and Phloxine B agar. The inoculated plates were incubated at room temperature. Pigmentation and colony form were read after one week.

Growth at different temperatures. Strains were plated on YPD medium with a replicator and grown at $16,22,30,37,40$ or $45^{\circ} \mathrm{C}$ for one week. The differences in growth were recorded as: + , for good growth; \pm for intermediate growth; and - , for no growth. Descriptive words for sectors and papillary growth were also employed.

Auxotrophy. Auxotrophic requirements were tested according to the standard procedure (Sherman et al., 1986).

Pulsed-field gel electrophoresis. The protocol for preparing DNA to be separated in pulsed-field gel electrophoresis has been published (Carle \& Olson, 1984). Orthogonal-field alteration gel electrophoresis (OFAGE) (Carle \& Olson, 1984) was used to resolve C. albicans chromosomes. Four different running conditions of OFAGE were applied to improve separations. The first condition consisted of a constant voltage or $7.5 \mathrm{~V} \mathrm{~cm}^{-1}$, approximately $100 \mathrm{~mA}$ at the start of the run, a $180 \mathrm{~s}$ pulse time, with $0.5 \times$ Tris/borate-EDTA cooling buffer at $10^{\circ} \mathrm{C}$ (Maniatis et al., 1982), $1.3 \%(\mathrm{w} / \mathrm{v})$ agarose and a $70 \mathrm{~h}$ running time. This condition was applied to resolve the shortest bands (or bottom, B, group of chromosomes). The second and third conditions were performed with the same voltage (and current) with a $1 \%$ agarose gel and two different pulse times, $160 \mathrm{~s}$ during a $24 \mathrm{~h}$ run and $250 \mathrm{~s}$ during a $39 \mathrm{~h}$ run, respectively. Both conditions were applied to the same gel and separated B and middle (M) groups of chromosomes simultaneously. The fourth condition included a constant voltage of $3 \mathrm{~V} \mathrm{~cm}^{-1}$, approximately $30 \mathrm{~mA}$ at the start of the run, a 30 -min pulse time, with $1 \%$ agarose and a $3-5 \mathrm{~d}$ running time, 
Table 1. The origin and characteristics of the non-germinative and colony form (morphological) strains of Candida albicans used

\begin{tabular}{|c|c|c|c|c|c|c|c|}
\hline \multirow[b]{2}{*}{ Mutant group } & \multirow{2}{*}{$\begin{array}{l}\text { Strain* } \\
\text { (UCLA) }\end{array}$} & \multirow{2}{*}{$\begin{array}{c}\text { Original } \\
\text { designation }\end{array}$} & \multirow[b]{2}{*}{ Origin of strain } & \multicolumn{3}{|c|}{ Characteristics $\dagger$} & \multirow[b]{2}{*}{ Reference } \\
\hline & & & & GT & Chl & Aux & \\
\hline \multicolumn{8}{|c|}{ A Spontaneous non-germinative } \\
\hline & $\underline{300}$ & $3153 \mathrm{~A}$ & Stock culture $\ddagger$ & + & + & $\mathrm{P}$ & \multirow[t]{2}{*}{$\begin{array}{l}\text { Buckley et al. (1982) and } \\
\text { Olaiya et al. }(1980)\end{array}$} \\
\hline & 301 & 6 & \multirow{4}{*}{$\begin{array}{l}\text { Spontaneous mutants } \\
\text { of } 300 \ddagger\end{array}$} & - & + & P) & \\
\hline & 302 & 09 & & - & - & $\mathrm{P}$ & \multirow[t]{2}{*}{ Olaiya et al. (1980) } \\
\hline & 303 & 9 & & - & + & P & \\
\hline & $300-\mathrm{SG}$ & 3153-SG & & - & + & $\mathbf{P}$ & Howard et al. (1986) \\
\hline \multicolumn{8}{|c|}{ B Induced non-germinative } \\
\hline & $\underline{307}$ & $\begin{array}{l}\text { Dye strain } \\
\text { (ATCC 36082) }\end{array}$ & Clinical isolate & + & + & $\mathrm{P}$ & Edwards et al. (1975) \\
\hline & 307D & - & $\begin{array}{l}\text { NTG-induced } \\
\text { mutant of } 307 \S\end{array}$ & - & - & $\mathbf{P}$ & Unpublished \\
\hline & $\underline{310}$ & CA-2\| & Clinical isolate & + & + & Lys ${ }^{-}$(leaky) & \multirow[t]{2}{*}{ Oblack et al. (1978) } \\
\hline & $\overline{311}$ & - & UV-induced & - & - & Lys $^{-}$(leaky) & \\
\hline & 312 & \} & mutants of 310 & - & - & $\begin{array}{l}\text { Lys }^{-} \mathrm{His}^{-} \\
\text {(leaky) }\end{array}$ & Unpublished** \\
\hline \multicolumn{3}{|c|}{ C Spontaneous morphological } & & & & & \multirow{3}{*}{ Rustchenko-Bulgac (1991) } \\
\hline & $\underline{3153 \mathrm{~A}}$ & $3153 \mathrm{~A}$ & $\begin{array}{l}\text { Subclone of } 3153 \mathrm{~A} \\
\text { (from D. Soll) }\end{array}$ & + & + & P) & \\
\hline & $\mathrm{m} 1-\mathrm{m} 20$ & - & $\begin{array}{l}\text { Spontaneous mutants } \\
\text { of } 3153 \mathrm{~A}\end{array}$ & + & + & $\mathrm{P}$ & \\
\hline
\end{tabular}

* These numbers are the Stock Culture numbers of strains in the UCLA Fungus Collection. The parental strains are underlined.

$\dagger$ Abbreviations: GT, germ tube formation (+ indicates various percentages of cells in populations formed germ tubes, - indicates a complete inability to form germ tube); Chl, chlamydospore production; Aux, auxotrophy (P, prototrophic; Lys ${ }^{-}$, lysine auxotroph; His-, histidine auxotroph),

\$The parental strain $300(3153 \mathrm{~A})$ and the spontaneous non-germinative mutants $(6,09,9)$ were received from S. J. Sogin (Olaiya et al., 1980) but the mutants were originally isolated by Helen Buckley (Buckley et al., 1982).

$\S$ The technique used to derive this mutant was described by Howard \& Dabrowa (1979); see Methods.

|| This designation is a duplication of one employed by Mattia et al. (1982) and is not the same as the one described by those investigators.

** These mutants were originally derived by Dr Donna Oblack, but results of work with them has not been published previously; see Methods for techniques used to derive the mutants.

providing a good separation of the three longest chromosomes (or top group, T).

Labelling with isotope, hybridization probe and hybridization. Labelling with $\left[\alpha_{-}^{32} \mathrm{P}\right] \mathrm{dATP}$ by the random priming method, Southern blot hybridizations and preparation of autoradiograms were carried out by standard methods (Maniatis et al., 1982). The ribosomal DNA fragment WOL-25 (M. J. McEachern and others, unpublished data) was used to assign the $C$. albicans long chromosome (VIII by our nomenclature) containing rDNA repeats.

\section{Results}

\section{Strains used in this study}

We analysed spontaneous and induced non-germinative mutants in comparison with their parental strains and 20 spontaneous morphological mutants of 3153A largely characterized previously for their electrophoretic karyotypes (Rustchenko-Bulgac, 1991). The characteristics of the three groups of mutants studied are given in Table 1. Group A consisted of non-germinative mutants that arose spontaneously from the parental strain 300 [which is a variant of $3153 \mathrm{~A}$ (see below)]. Non-germinative mutants of the sort represented by 301,302 and 303 have been reported to occur at a frequency of $1-2 \%$ (Buckley et al., 1982). Strain 300-SG was observed at a single instance amongst $10^{3}$ colonies of strain 300 (Howard et al., 1986). Group B consisted of the NTG- and UVinduced non-germinative mutants and their parental strains 307 and 310, respectively. The colony form mutants (group C) arose spontaneously from their parental strain $3153 \mathrm{~A}$ at a frequency of about $1.4 \%$. Two clinical isolates, $3153 \mathrm{~A}$ and WO-1 were used as reference strains because of their well analysed chromosomal patterns.

\section{Establishment of the identity of clinical isolates and the fact that the mutants were related to the indicated parents}

The mutants and their putative parents were analysed by Southern blot hybridization of total cellular DNA with the $C$. albicans-specific mid-repeat sequence Ca3 (Sadhu et al., 1991). The results established that the germinationdeficient mutants had arisen from the parents indicated in Table 1 (data not shown). Parental strains 300, 307 

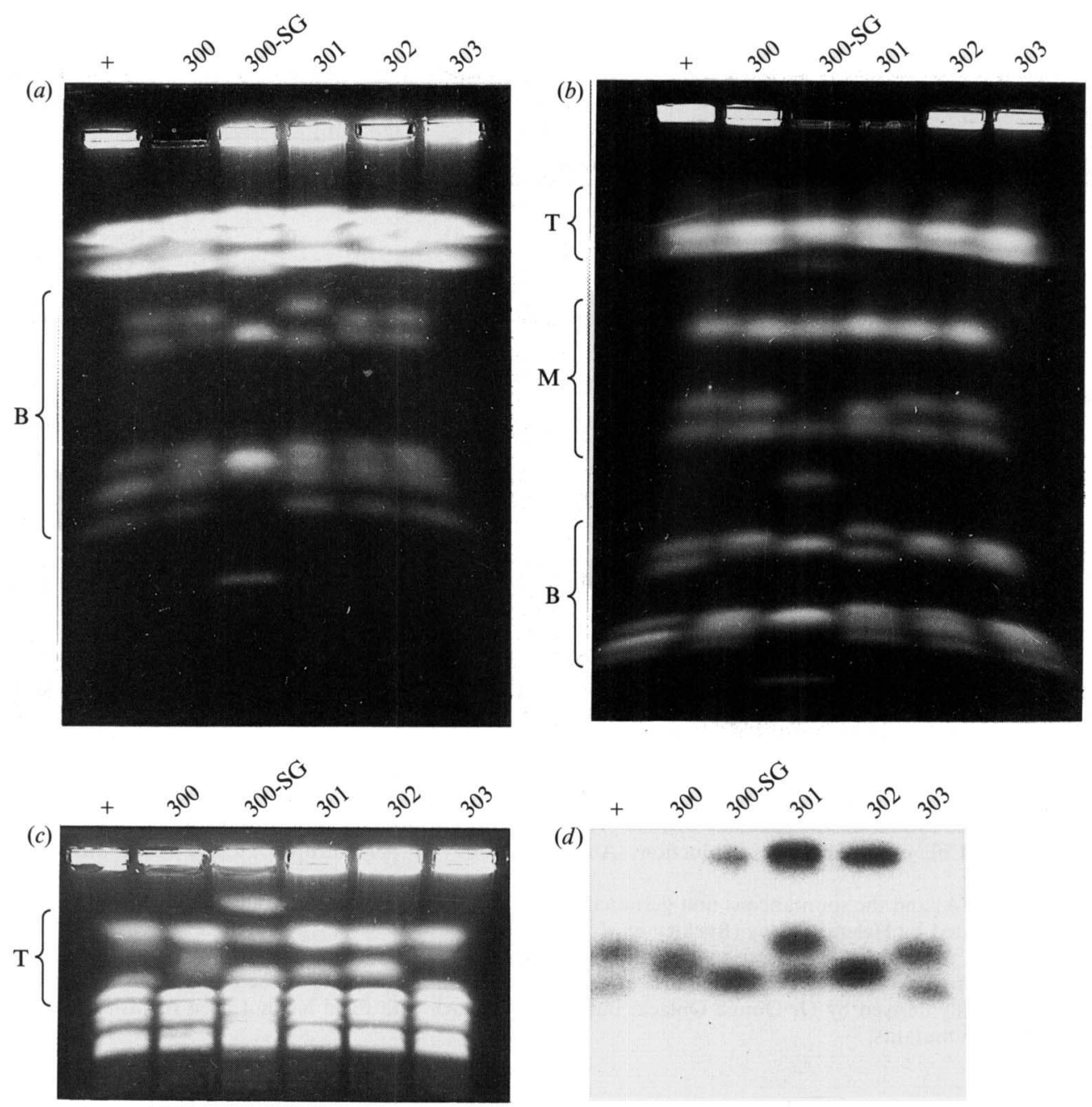

Fig. 1. Chromosomal patterns of spontaneous non-germinative mutants $301,302,303,300$-SG, their parental strain, 300, and the predecessor strain, 3153A (+). (a) The shortest chromosomes, bottom group (B), were separated under the first condition (see Methods). The remaining chromosomes are compressed in runs under the first condition. $(b)$ The shortest and middle-sized chromosomes, or middle group (M) separated under the second and third condition on the same gel (see Methods). (c) The longest chromosomes or top group ( $\mathrm{T}$ ) separated under the fourth condition (see Methods). The chromosomes, other than the longest, are compressed into two thick bands. (d) Signals of chromosomes VIII were revealed after hybridization of the filter shown in panel (c) with probe WOL-25 (rDNA).

and 310 , were not related, but 300 and $3153 \mathrm{~A}$ had the same pattern (data not shown).

\section{Electrophoretic karyotypes of the isolates 300, 307 and 310}

The chromosomal patterns of all three isolates, 300, 307 and 310, are presented in Figs 1 and 2. The chromosomes of the three strains ran along side those of strain 3153A whose electrophoretic karyotype has been extensively examined with chromosomal markers and shown to have eight pairs of chromosomes of which five homologues ran separately in pairs and three co-migrated (Rustchenko-Bulgac, 1991; see Fig. 2). On this basis, a direct comparison between related strains $3153 \mathrm{~A}$ and 300 was possible. We also used $3153 \mathrm{~A}$ as a reference strain for all parentals because we had compared earlier electrophoretic karyotypes of four clinical isolates including 3153A using chromosomal markers and found that despite certain variability in length, the basic general pattern of chromosomes was preserved (RustchenkoBulgac, 1991). As seen in Figs 1-3, all three strains, 300, 307 and 310 , had multiple differences in band positions in comparison with $3153 \mathrm{~A}$ and among themselves.

The differences between $3153 \mathrm{~A}$ and 300 chromosomal patterns are of special interest. Both strains were considered to be the same (Table 1), but were maintained in different laboratories for some time. The results of 

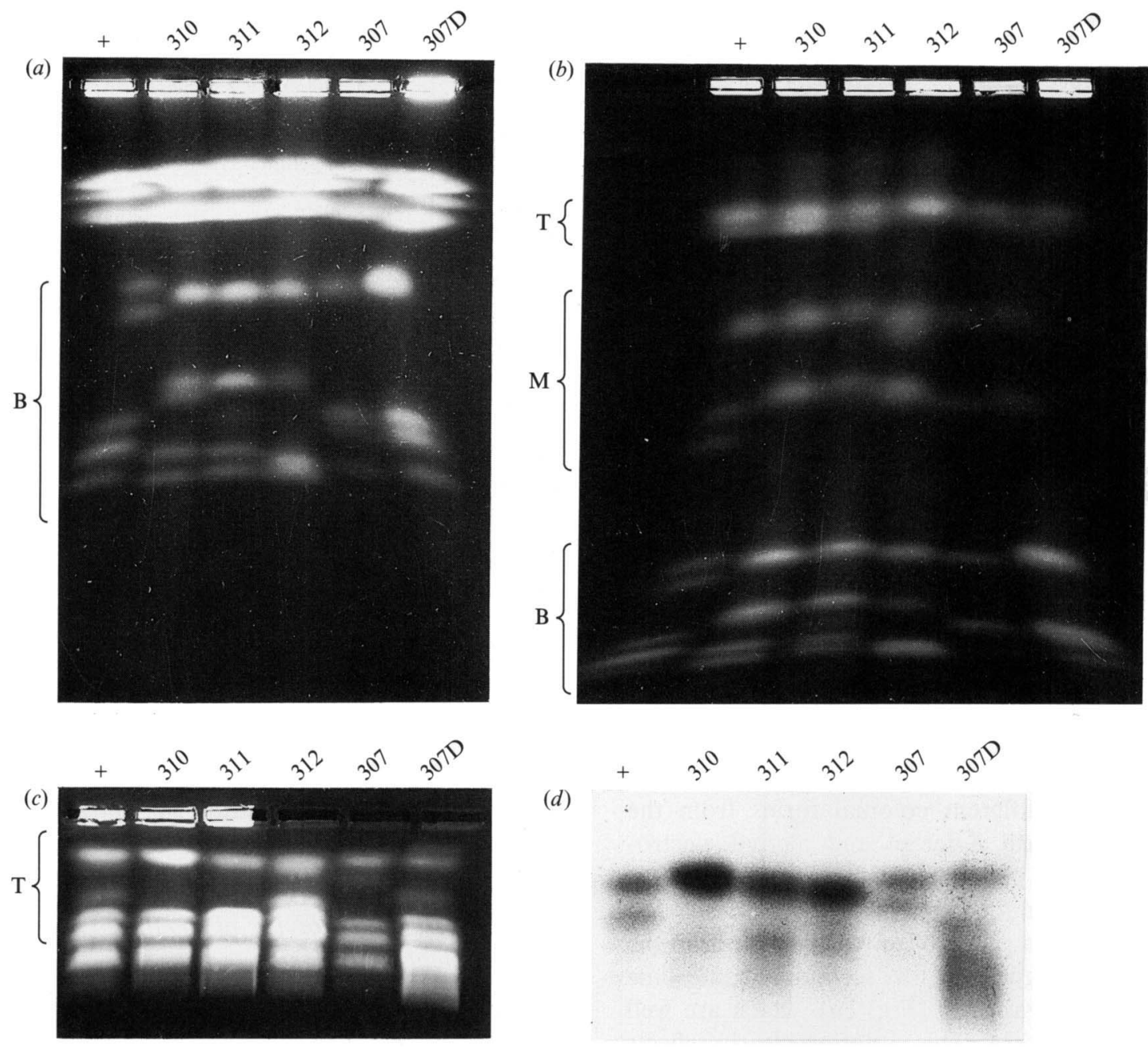

Fig. 2. Chromosomal patterns of induced non-germinative mutants $307 \mathrm{D}, 311$ and 312 , and their parental clinical isolates, 307 and 310 , respectively. The clinical isolate $3153 \mathrm{~A}(+)$ was used as a reference strain. Panels $(a-d)$ are as described in the legend to Fig. 1.

testing the identity with the specific probe $\mathrm{Ca} 3$ confirmed that they are the same strain. Nevertheless, their electrophoretic karyotypes revealed multiple differences. Both homologues of the most frequently altered chromosome VIII (Rustchenko-Bulgac, 1991; Asakura et al., 1991; Iwaguchi et al., 1992) had different positions (Fig. $1 c, d$, and see Fig. 3 for nomenclature of chromosomes). Chromosome III, which has been found to be the second most frequently altered chromosome (RustchenkoBulgac, 1991) is represented in strain 300 by two homologues of unequal brightness with IIIa positioned differently. Because the brightness of IIIa is lower than expected by comparison with the analogous chromosome in 3153A (the total amount of DNA loaded in both wells, for $3153 \mathrm{~A}$ and for 300 being very close) we cannot regard this pattern to be of aneuploid origin. Taking into account that changes from separated homologues into co-migrating ones are typical for this chromosome
(Rustchenko-Bulgac et al., 1990; Rustchenko-Bulgac, 1991; also see Fig. 3), one can conclude that this position on the gel indicates the presence of several different karyotypes in the population. One pattern probably contains both IIIa and $b$ co-migrating. Other patterns could be one or other of the following: the homologues distributed in a manner similar to these of $3153 \mathrm{~A}$ but with IIIa running more slowly; homologues co-migrating in an unusual position, in a manner similar to those of $300-\mathrm{SG}$ (Fig. 3); and, finally, chromosome III is monosomic with only chromosome IIIa present and unusually positioned. Rare instances of spontaneous monosomy have been reported (Rustchenko-Bulgac, 1991). We do not know which of the several possible karyotypes are present in populations of strain 300 and contribute to the pattern of chromosomes displayed. The assumption of a mixed composite karyotype is also supported by the diversity of its colony forms in the 


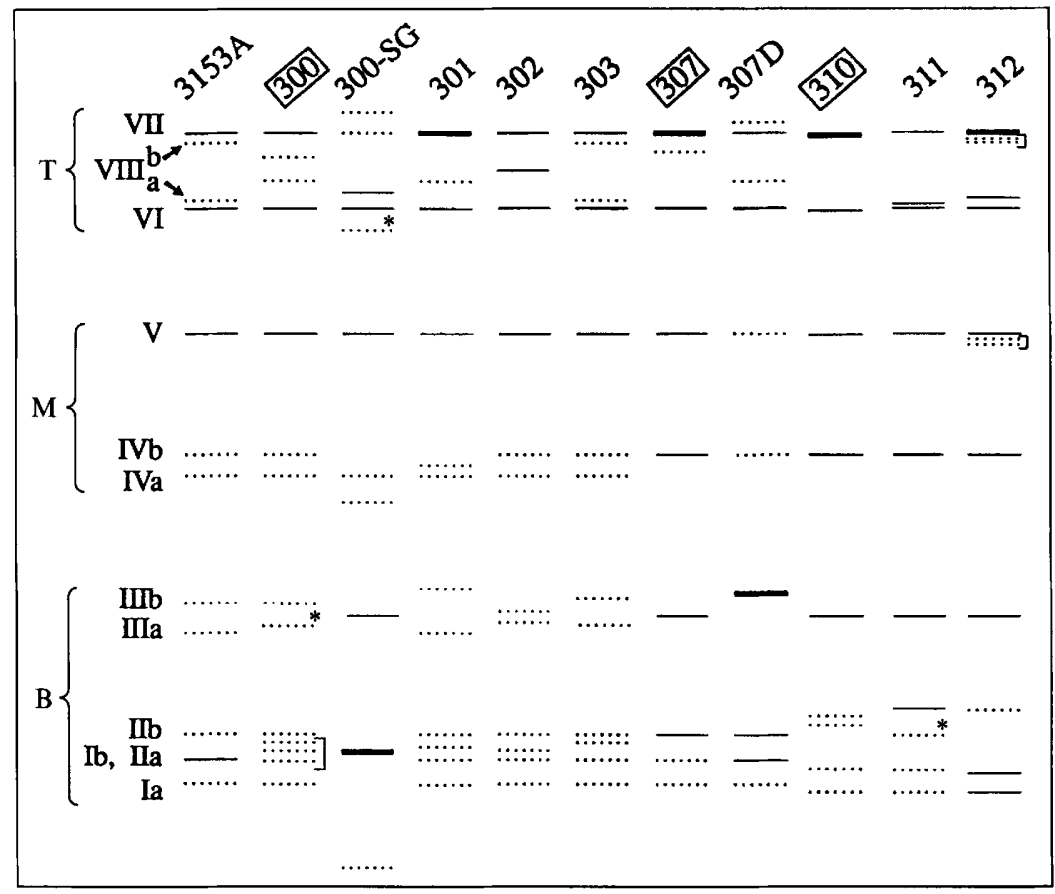

Fig. 3. Schematic representation of the electrophoretic karyotypes of parental strains 300 , 307 and 310 , and their progenies: spontaneous non-germinative mutants $301,302,303,300$ SG; UV-induced non-germinative 307D; and NTG-induced non-germinative 311 and 312 , respectively. Parental strains are in boxes. The chromosomal pattern of clinical isolate $3153 \mathrm{~A}$ is presented as a reference. The assignments of chromosomes from I to VIII and the homologous pairs, $a$ and $b$, are indicated on the left. Dotted, thin and thick lines correspond, respectively, to one, two or more than two chromosomes, the thickness of the lines being related to the number of chromosomes. Assignments of individual chromosomes with their markers and approximate sizes have been published previously (RustchenkoBulgac, 1991). When the intensity of ethidium bromide staining was lower than expected for a single homologue, the corresponding band was marked with an asterisk. Groups of unresolved bands are marked with brackets.

population, an observation that correlates with our earlier finding that different colonial forms from the same population reveal different and altered electrophoretic karyotypes (Rustchenko-Bulgac, 1991). An additional difference in the karyotypes of strains 300 and $3153 \mathrm{~A}$ is that there is a group of unresolved bands in the area of the homologues of the second chromosome (bottom group) of strain 300 (Fig. 1a), which are well separated in strain $3153 \mathrm{~A}$. This situation clearly reflects a number of differently sized but closely running bands which probably represent various alignments of chromosome II in different cells in the population, a situation which is similar to that displayed by highly unstable mutant m500 reported previously (Rustchenko-Bulgac, 1991). Some other differences in the karyotypes of strains 300 and 3153A are shown in the schematic presentation of band separations (Fig. 3). The condition of chromosome III together with a group of unresolved bands around the position of chromosome II represent the composite electrophoretic karyotype of strain 300 and indicates the presence of different karyotypes in the population (i.e. a mixed population). As was reported (Rustchenko-Bulgac, 1991), the customary way of subculturing by picking one subclone (colony) from a plate leads to selection of an altered electro-karyotype as well as colonial phenotype of 3153A. In contrast, maintaining Candida strains as populations leads to the proliferation and accumulation of the spontaneous variants with various changes in electrophoretic karyotypes which are the products of only a few unstable cells and thus, any observable chromosomal alterations escape detection. However maintaining unstable variants of natural isolates, which strain 300 apparently is, would lead to the observation of a mixture of karyotypes.

\section{Electrophoretic karyotypes of spontaneous and induced non-germinative progenies}

(i) Spontaneously altered electrophoretic karyotypes of strains 301, 302, 303 and 300-SG

Observation of the spontaneous mutants of 300,301 , 302,303 and $300-\mathrm{SG}$, revealed several peculiarities in their karyotypes that reflected components of the collective karyotype of strain 300 (see for example, chromosome II; Figs 1-3). Outstanding differences were found in the banding pattern of 300-SG. Whereas mutants 301, 302 and 303 had bands in slightly different positions, some of the bands of 300-SG occurred in completely different positions. The banding pattern of $\mathrm{B}$ and $\mathrm{M}$ groups of chromosomes of 300-SG was compared with that of WO-1 (Fig. 4). which is remarkably altered in comparison with other clinical isolates and has multiple translocations (Rustchenko-Bulgac, 1991). Possible hybrid chromosomes in 300-SG similar to those in WO-1 remain to be uncovered by using chromosomal markers (Rustchenko-Bulgac, 1991). Besides the pronounced alterations in both karyotypes, an additional similarity between WO-1 and 300-SG lies in the fact that both strains roughly maintain the range of sizes and a basic structure of the genome which consists of three groups of chromosome sizes (Fig. 3). A faint band in an unusual position under the top group is probably an 


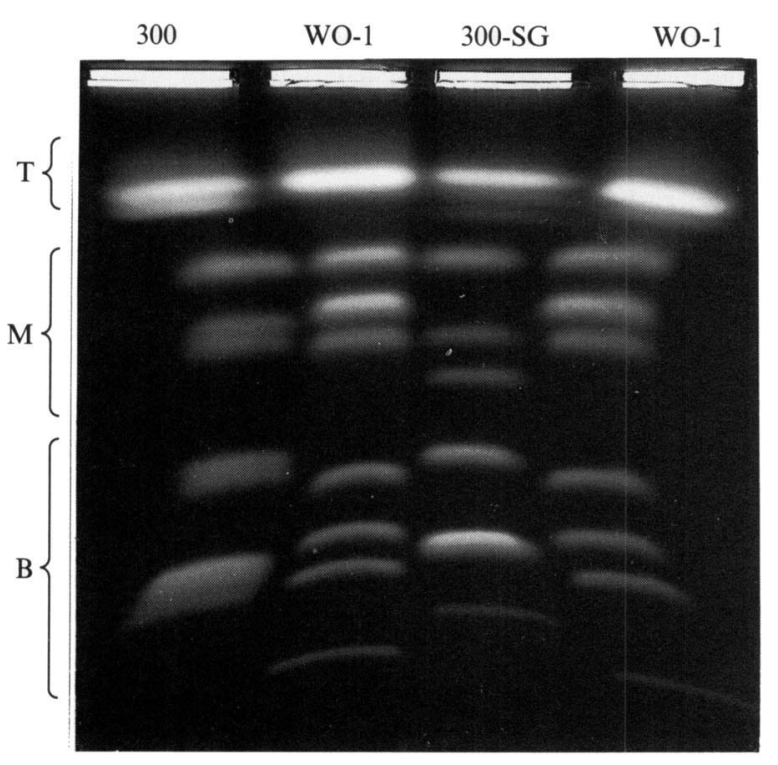

Fig. 4. Chromosomal patterns of clinical isolate WO-1, strain 300 and its spontaneous non-germinative mutant $300-\mathrm{SG}$. $\mathrm{B}$ and $\mathrm{M}$ group chromosomes were well-separated under the second and third conditions (see Methods), the T group chromosomes are compressed.

indication of a mixed karyotype as suggested above for chromosome IIIa.

The chromosomal patterns of 301, 302 and 303, which have been reported to be haploids (Olaiya et al., 1980) under different designations 6, 09 and 9, respectively (Table 1), resembled typical diploids with each chromosome represented by two homologues as compared to the related reference strain 3153A. Again, this disagreement with the earlier report could be due to the prolonged period of maintenance of the mutants which may have been isolated as haploids (or aneuploids with multiple monosomia) and subsequently restored to the diploid state during subculture. However, it would be difficult to explain in this way the large number of similarities in chromosomal patterns of 301, 302 and 303 because such similarities could only have resulted from a large number of independent events occurring during diploidization.

(ii) Induced altered electrophoretic karyotypes of 307-D, 311 and 312

The electrophoretic karyotypes of all three induced mutants (see Table 1) were altered in many ways from their parental strains 307 and 310 (Figs 2 and 3). If a thick band in the position of chromosome II contains more than three chromosomes, then 307D would be an aneuploid for the $2 n+x$ type. Mutant 311 has a weak band (marked with asterisks, in the B group), an indication of a mixed population in which not all cells possess bands in these positions. Also, mutant 312 has some unresolved bands in the middle and bottom groups, a feature of collective karyotypes described previously for the unstable mutant m500 (Rustchenko-Bulgac, 1991) and discussed above for strain 300.

\section{Altered phenotypes of spontaneous morphological mutants and spontaneous and induced non-germinative mutants}

\section{(i) Colonial morphology}

The three parental strains, 300, 307 and 310, had individual colony morphologies under standard conditions. The spontaneous and induced progenies showed altered and individual colonial morphologies in comparison with their parents under the same standard conditions. An example of colonies of one non-germinative mutant from each parental strain, as well as parental forms are shown in Fig. 5. All three parental strains and some of their progenies displayed mixtures of
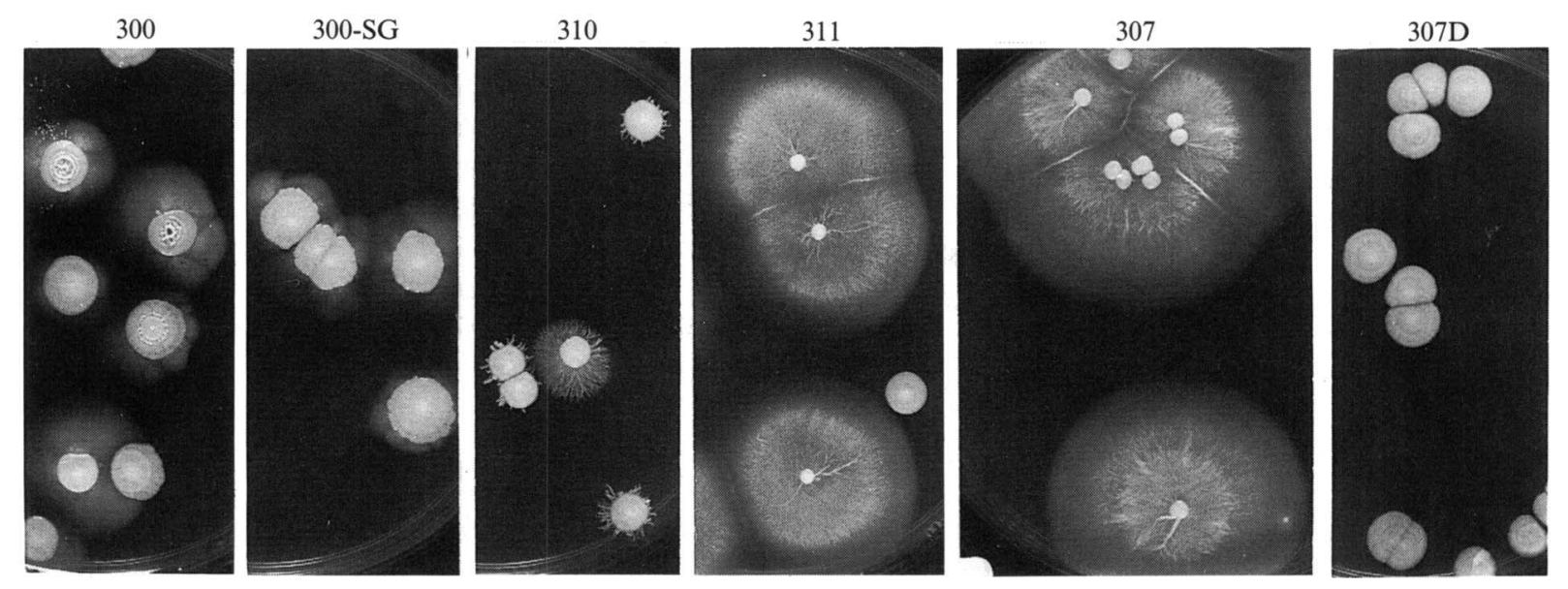

Fig. 5. Colonial morphologies of clinical isolates 307, 310, 300 (the unstable variant of 3153A) and some selected spontaneous and induced non-germinative progenies. See Table 1 for the relationship between strains. 


\section{Table 2. Summary of colonial morphology on $L B C$ medium}

Each strain has an individual colony appearance or is represented by a mixture of several different and individual forms (see representative colonial forms in Fig. 5). Spontaneous morphological mutants $\mathrm{m} 1-\mathrm{m} 20$ were characterized previously (Rustchenko-Bulgac et al., 1990; Rustchenko-Bulgac, 1991).

\begin{tabular}{ll}
\hline \hline Strain no.* & State of colonial population $\dagger$ \\
\hline$\frac{3153 \mathrm{~A}}{300}$ & Uniform with small mycelium \\
$\frac{301}{302}$ & Mixed \\
303 & Uniform with sectoring \\
$300-\mathrm{SG}$ & Uniform with sectoring \\
$\frac{307}{307 D}$ & Uniform with sectoring \\
$\frac{310}{311}$ & Uniform with sectoring \\
312 & Uniform with huge mycelium \\
\hline \hline
\end{tabular}

* Parental strains are underlined. See Table 1 for relationship between strains.

$\dagger$ Uniform, colonies with the same morphological appearance; mixed, colonies of various forms; mycelium, colonies with filamentous edges; sectoring, colonies with areas of morphology different from overall appearance.

different colonial forms (Table 2). Mixed colonial populations usually corresponded to mixed electrophoretic karyotypes, e.g. in parental strain 300 or induced mutants, 311 or 312 . Spontaneous mutant 300 SG was initially identified by its small colony size and was described as a slow-growing mutant (Howard et al., 1986), but over time during maintenance at $4{ }^{\circ} \mathrm{C}$ in a refrigerator both normal growth rate and colonial size have been restored (Fig. 5).

The colonial forms of spontaneous morphological mutants $\mathrm{m} 1-\mathrm{m} 20$, as well as the uniformity of their populations were reported previously (RustchenkoBulgac et al., 1990; Rustchenko-Bulgac, 1991).

(ii) Germ tube formation and chlamydospore production Each of the germination-deficient mutants has retained the non-germination phenotype for many years (Howard et al., 1986). Although each of the non-germinative mutants formed chlamydospores and pseudohyphae when studied initially (unpublished observation), strains 302, 307D, 311 and 312 have subsequently lost the ability to form chlamydospores (Table 1), though they all still form pseudohyphae. All of the colony form mutants (m1-m20) formed germ tubes (although the percentage of yeast cells germinating ranged from 27 to $91 \%$ among the mutants), chlamydospores and pseudohyphae (Table $1)$.

(iii) Growth on BiGGY agar and on LBC agar with Phloxine B

Strains were plated for individual colonies $(10-20 \mathrm{per}$ plate) on BiGGY agar and on LBC agar with Phloxine B. There was a great deal of variation in colonial appearance, not only among the strains but also between the colonies of a single strain. On BiGGY agar variations among strains and between colonies were seen with regard to colour (tan, brown or dark brown), texture (smooth, umbonate or wrinkled) and edge of colony (entire or filamentous). Variations also occurred among strains and between colonies on the Phloxine Bcontaining medium. Colour ranged from light pink to red, sometimes in a streaked (sectored) pattern. Colony surfaces were variously sized, usually smooth and occasionally umbonate. The edges of the colonies were entire, i.e. filamentation was not seen. The results of testing strains on BiGGY and on LBC agar with Phloxine $\mathbf{B}$ are presented in Table 3.

\section{(iv) Amino-acid deficiency}

All strains were tested for their auxotrophy as described in Methods. Parental strain 310 and its induced progeny, 311 , had leaky requirements for lysine. Another induced progeny, 312, had an additional leaky requirement for histidine. The remaining 28 strains (3 parental, 24 spontaneous mutants and 1 induced mutant) were prototrophs.

(v) Temperature tolerance of non-germinative and morphological mutants

All the parental strains, 3153A, 300, 307 and 310, grew over a broad temperature range of $16-45^{\circ} \mathrm{C}$ (Table 4). Spontaneous non-germinative mutants (Group A) grew almost as well except for two instances of diminished growth at elevated temperatures (301 and 300-SG). Nine of the spontaneous morphological mutants showed no difference from their parental strain, except for slightly diminished growth of three of them ( $\mathrm{m} 1, \mathrm{~m} 3$ and $\mathrm{m} 11)$ at $45^{\circ} \mathrm{C}$. The growth of 10 of the morphological mutants was inhibited at $45^{\circ} \mathrm{C}$ and some strains also grew poorly at $40{ }^{\circ} \mathrm{C}$. The growth of some morphological mutants was slightly diminished at $16^{\circ} \mathrm{C}$, showing a narrower range of tolerable temperatures than the parental strain. In this respect, they were similar to the induced nongerminative mutant 307D which also grew over a somewhat restricted range of temperatures. The induced mutants 311 and 312 could not grow normally at any of the temperatures and often grew in the form of papillae which indicated mixed populations of cells with mixed responses to growth conditions.

\section{Probing with $r D N A$}

As demonstrated previously, the chromosome that most frequently changed in natural isolates and spontaneous morphological mutants was chromosome VIII, which contains rDNA repeats (Rustchenko-Bulgac, 1991; Asa- 
Table 3. Colonial morphology of germination-deficient and morphological mutants, and their parental strains on BiGGY agar and Phloxine B agar

\begin{tabular}{|c|c|c|c|}
\hline \multirow[b]{2}{*}{ Strain* } & \multicolumn{3}{|c|}{ Morphology on BiGGY agar } \\
\hline & Colour & Surface & Edge $\dagger$ \\
\hline$\underline{3153 \mathrm{~A}}, \underline{300}$ & Brown & Umbonate & Entire \\
\hline $\mathrm{m} 1, \mathrm{~m} 2$ & Tan to brown§ & $\begin{array}{l}\text { Umbonate or } \\
\text { wrinkled }\end{array}$ & $\begin{array}{l}\text { Entire or } \\
\text { filament }\end{array}$ \\
\hline $\mathrm{m} 3, \mathrm{~m} 15$ & Brown & Umbonate & Filament \\
\hline $\mathrm{m} 4$ & Brown & $\begin{array}{l}\text { Umbonate or } \\
\text { wrinkled }\end{array}$ & Filament \\
\hline $\begin{array}{l}\mathrm{m} 5, \mathrm{~m} 6, \mathrm{~m} 9, \mathrm{~m} 11, \\
301,302,303, \underline{310}\end{array}$ & Brown & Umbonate & Entire \\
\hline $\mathrm{m} 7, \mathrm{~m} 19$ & Brown & $\begin{array}{l}\text { Umbonate or } \\
\text { wrinkled }\end{array}$ & $\begin{array}{r}\text { Entire or } \\
\text { filament }\end{array}$ \\
\hline $\mathrm{m} 8, \mathrm{~m} 17$ & $\begin{array}{l}\text { Brown to } \\
\text { dark brown }\end{array}$ & $\begin{array}{l}\text { Umbonate or } \\
\text { wrinkled }\end{array}$ & $\begin{array}{r}\text { Entire or } \\
\text { filament }\end{array}$ \\
\hline $\mathrm{m} 10$ & Brown & $\begin{array}{l}\text { Umbonate to } \\
\text { wrinkled }\end{array}$ & $\begin{array}{r}\text { Entire to } \\
\text { filament }\end{array}$ \\
\hline $\mathrm{m} 12$ & Dark brown & Wrinkled & Filament \\
\hline $\mathrm{m} 13$ & Light tan & Umbonate & Entire \\
\hline $\mathrm{m} 14$ & Brown to $\tan$ & $\begin{array}{l}\text { Papillate to } \\
\text { wrinkled }\end{array}$ & $\begin{array}{r}\text { Entire or } \\
\text { filament }\end{array}$ \\
\hline $\mathrm{m} 16$ & Brown & Umbonate & $\begin{array}{r}\text { Entire or } \\
\text { filament }\end{array}$ \\
\hline $\mathrm{m} 18$ & Brown & Wrinkled & Entire \\
\hline $\mathrm{m} 20$ & Tan & Umbonate & Entire \\
\hline 300-SG & Dark brown & $\begin{array}{l}\text { Umbonate or } \\
\text { wrinkled }\end{array}$ & Entire \\
\hline$\underline{307}$ & Tan & Wrinkled & Filament \\
\hline 307D & $\operatorname{Tan}$ & Wrinkled & Entire \\
\hline 311 & Tan & Smooth & Entire \\
\hline \multirow[t]{3}{*}{312} & Dark brown & Umbonate & Entire \\
\hline & \multicolumn{3}{|c|}{ Morphology on Phloxine B agar } \\
\hline & Colour & Surface & Edge $†$ \\
\hline $\begin{array}{c}\frac{3153 \mathrm{~A}}{302}, 303,300,300-\mathrm{SG}, 301 \\
307 \mathrm{D}, 310\end{array}$ & $\begin{array}{l}\text { Light pink with } \\
\text { dark pink rim }\end{array}$ & Smooth & Entire \\
\hline $\begin{array}{l}\mathrm{m} 1, \mathrm{~m} 2, \mathrm{~m} 3, \mathrm{~m} 4, \mathrm{~m} 5, \\
\mathrm{~m} 6, \mathrm{~m} 7, \mathrm{~m} 15, \mathrm{~m} 16, \mathrm{~m} 17\end{array}$ & $\begin{array}{l}\text { Pink (sectored) } \\
\text { with dark pink rim }\end{array}$ & Smooth & Entire \\
\hline $\mathrm{m} 8, \mathrm{~m} 9, \mathrm{~m} 10, \mathrm{~m} 11$ & $\begin{array}{l}\text { Pink to white } \\
\text { with dark pink rim§ }\end{array}$ & Smooth & Entire \\
\hline $\mathrm{m} 12$ & Pink to white & Smooth & Entire \\
\hline $\mathrm{m} 13$ & Pink & Smooth & Entire \\
\hline $\mathrm{m} 14$ & Pink (sectored) & Smooth & Entire \\
\hline $\mathrm{m} 18, \mathrm{~m} 19, \mathrm{~m} 20$ & $\begin{array}{l}\text { Pink } \| \text { with } \\
\text { dark pink rim }\end{array}$ & Smooth & Entire \\
\hline 311 & $\begin{array}{l}\text { Pink with } \\
\text { dark pink rim }\end{array}$ & $\begin{array}{l}\text { Tiny colony } \\
\text { smooth }\end{array}$ & Entire \\
\hline 312 & $\begin{array}{c}\text { Dark pink with } \\
\text { dark pink rim }\end{array}$ & $\begin{array}{l}\text { Tiny colony } \\
\text { smooth }\end{array}$ & Entire \\
\hline
\end{tabular}

* For the relationship between strains, see Table 1.

$\doteqdot$ Entire edge indicates no peripheral filamentation.

$\$$ The umbonate centre was a darker shade of brown than the rest of the colony.

$\S$ Mixture of colonies over the range indicated.

$\|$ Many shades with sectoring.

kura et al., 1991; Iwaguchi et al., 1992). Probing the nongerminative mutants and their parents with rDNA (Figs $1 d$ and $2 d$ ) served to distinguish among bands in group $\mathrm{T}$ and revealed a similar situation with regard to chromosome VIII as reported for morphological mu- tants. Thus, all three parental strains, 300, 307 and 310, had different patterns for chromosome VIII and their progenies had different alterations in chromosomes VIII in comparison with the parental strains and among themselves. 
Table 4. Growth of germination-deficient and morphological mutants at different temperatures in 1 week on YPD medium

\begin{tabular}{|c|c|c|c|c|c|c|}
\hline \multirow[b]{2}{*}{ Group } & \multirow[b]{2}{*}{ Strain* } & \multicolumn{5}{|c|}{ Growth at: $\dagger$} \\
\hline & & $16^{\circ} \mathrm{C}$ & $22{ }^{\circ} \mathrm{C}$ & 30 and $37^{\circ} \mathrm{C}$ & $40^{\circ} \mathrm{C}$ & $45^{\circ} \mathrm{C}$ \\
\hline \multicolumn{7}{|c|}{ A Spontaneous non-germinative } \\
\hline & $\underline{300}$ & + & + & + & + & + \\
\hline & $\overline{301}$ & + & + & + & + & \pm \\
\hline & 302 & + & + & + & + & + \\
\hline & 303 & + & + & + & + & + \\
\hline & $300-S G$ & + & + & + & $\stackrel{ \pm}{\text { Opaque }}+$ & - \\
\hline \multicolumn{7}{|c|}{ B Induced non-germinative } \\
\hline & 307 & + & + & + & + & + \\
\hline & $307 \mathrm{D}$ & \pm & + & + & $\stackrel{ \pm}{\text { Opaque }}$ & Some pap \\
\hline & $\underline{310}$ & + & + & + & + & + \\
\hline & $\overline{311}$ & pap & pap & $\stackrel{ \pm}{\text { big sectors }}$ & $\begin{array}{l} \pm \\
\text { Opaque } \\
\text { white sectors }\end{array}$ & Few pap \\
\hline & 312 & $\begin{array}{l}\text { pg } \\
\text { pap }\end{array}$ & $\stackrel{ \pm}{\text { pap }}$ & pg & pap & - \\
\hline \multirow{9}{*}{ C Spontaneous $r$} & morphological & & & & & \\
\hline & $\frac{3153 \mathrm{~A}, \mathrm{~m} 4-\mathrm{m} 6}{\mathrm{~m} 9, \mathrm{~m} 15, \mathrm{~m} 17}$ & + & + & + & + & + \\
\hline & $\mathrm{m} 1, \mathrm{~m} 3, \mathrm{~m} 11$ & + & + & + & + & $\stackrel{ \pm}{\text { pap }}$ \\
\hline & $\mathrm{m} 2$ & \pm & + & + & pap & - \\
\hline & $\mathrm{m} 7, \mathrm{~m} 10, \mathrm{~m} 16$ & $\overline{+}$ & + & + & + & pg \\
\hline & $\mathrm{m} 8, \mathrm{~m} 12$ & \pm & + & + & + & - \\
\hline & $\mathrm{m} 13, \mathrm{~m} 18, \mathrm{~m} 19$ & $\bar{t}$ & + & + & $\mathrm{pg}$ & - \\
\hline & $\mathrm{m} 14$ & \pm & + & + & $\begin{array}{l}\text { f micro. } \\
\text { pap }\end{array}$ & - \\
\hline & $\mathrm{m} 20$ & + & + & + & \pm & - \\
\hline
\end{tabular}

* See Table 1 for relationship between strains.

$\dagger$ Symbols: +, growth; -, no growth; \pm , diminished growth; pg, poor growth; pap, papillae of different sizes instead of confluent growth; f micro. pap, a few microscopic papillae instead of confluent growth; opaque, creamy or grey colour, clearly different from usual white.

¥ The change in colour in our experiment is not necessarily the same as the white-opaque transition described for strain WO1 (Soll et al., 1991); also the opaque phenotype is induced at an elevated temperature, whereas the white-opaque transition of WO-1 is repressed at $37^{\circ} \mathrm{C}$.

\section{Discussion}

Many authors have described spontaneous and induced variations in the form of colonies in laboratory strains and natural isolates of $C$. albicans (for a review, see Odds, 1988). Brown-Thompsen (1968) reported an unstable variant that produced high frequencies of different colonial forms. Also, Slutzky et al. (1985) reported that five UV-induced colonial variants 'switched' from one phenotype to another at various rates. In addition, a high frequency of reversible switching between white and opaque phenotypes has been studied extensively and reviewed recently (Soll et al., 1991). In a systematic study, Rustchenko-Bulgac demonstrated an association between stable and unstable spontaneous morphological mutants and electrophoretic karyotypes (Rustchenko-Bulgac et al., 1990; Rustchenko-Bulgac, 1991).
A distinct feature of C. albicans is that different clinical isolates have various electrophoretic karyotypes, as described by Merz et al. (1988) and others (for a rewiew, see Merz, 1990), and investigated in detail for the four clinical isolates, 3153A, WO-1, C9 and FC18 (Rustchenko-Bulgac, 1991). In addition to having varied electrophoretic karyotypes, these four clinical isolates also had distinct colonial morphologies, consistent with the result with spontaneous morphological mutants. We assumed that the variable colonial morphology was due to genetic differences, some of which were reflected in chromosomal patterns. In accordance with this assumption is the present observation that isolates 307 and 310 have different chromosomal patterns and display individual colonial morphologies under our standard conditions (Figs 1-3 and 5). A third strain, 300, is a subclone of clinical isolate $3153 \mathrm{~A}$ having an altered electrophoretic karyotype. It displays a mixture of several 
colonial morphologies in its population (Fig. 5) and its electrophoretic karyotype is collective, reflecting apparently individual alterations of several different karyotypes recovered from populations of its cells (Figs 1 and 3).

In this work, we expanded our previous analyses of chromosomal alterations to include a group of spontaneous and UV- and NTG-induced non-germinative mutants (see Table 1), which have remained stable for more than 12 years despite repeated laboratory manipulations (e.g. Dabrowa et al., 1990a). We initiated a more complete study of the relationship between multiply altered phenotypes and chromosomal changes (see below). Overall, induced and spontaneous non-germinative mutants revealed the following chromosomal patterns: mixed or collective electrophoretic karyotypes (e.g. 311,312 and possibly $300-\mathrm{SG}$, Figs $2 a, b$ and $1 b$, respectively); high variability of chromosome VIII homologue patterns (Figs $1 c, d$ and $2 c, d$ ); same lengths of previously deviated homologues, probably duplications of one and the loss of the other (e.g. chromosomes III and VIII in 300-SG, or II in 311, Fig. $1 b, d$ and $1 a$, respectively); relatively small deletions and insertions which slightly changed the positions of two homologues (e.g. note the pattern of chromosome II in 301, 302 and 303, Fig. $1 a, b$ ); and, rarely, some significant changes in positions of bands (300-SG, Figs 1 and 4). The mechanism(s) of chromosomal changes encountered in our work remains unknown. Nevertheless, it is clear that they did not result from reciprocal translocations between ectopically located copies of $\mathrm{Ca} 3$, because all the related strains preserved the same hybridization pattern with $\mathrm{Ca} 3$ in the EcoRI digest (see Results). All electrophoretic karyotypes are schematically summarized in Fig. 3 and analysed in more detail in Results. All of these changes have been observed for the 20 spontaneous morphological mutants, m1-m20, of 3153A included in this study, as well as for clinical isolates (Rustchenko-Bulgac, 1991). The fact that all seven nongerminative mutants showed individually altered colonial forms (Fig. 5) indicates a parallel between the 20 spontaneous colony form mutants and the non-germinative ones. Moreover, strains with mixed colonial populations, 300, 311 and 312 (Table 2), have cumulative, collective karyotypes (Fig. 3). These facts taken together are in agreement with the previous observation that altered karyotype and colonial morphology are associated. The fact that all spontaneous non-germinative mutants displayed altered colonial morphology and had patterns of low and high phenotypic variabilities (see below) indicates that non-germinative mutants represent another phenotypic consequence of genomic instability in C. albicans.

The connection between altered colonial form and altered electrophoretic karyotype is a well-established fact (Rustchenko-Bulgac, 1991). We have also obtained a substantial amount of data on altered microscopic morphology of cells and rates of growth associated with altered karyotypes (Rustchenko-Bulgac et al., 1990; Rustchenko-Bulgac, 1991). To investigate further the dependence of Candida phenotypes upon changing chromosomal patterns, we compared in this study several morphological and physiological properties of spontaneous and induced non-germinative mutants as well as spontaneous morphological mutants with their parents.

C. albicans is known to grow as a budding yeast (blastoconidia), as a pseudohyphae of elongated yeast cells, and as a true septate hypha (Meyer et al., 1984; Odds, 1988). The true hyphal form of growth is initiated by germination of the blastoconidia (Dabrowa \& Howard, 1983; Szaniszlo et al., 1983) and interest in this germination event centres in the developmental biology of the fungus and in the potential relevance to pathogenicity, though there is no evidence that germ tube formation is an essential virulence factor (Cutler, 1991). A large number of factors are known to control blastoconidial germination by $C$. albicans (Dabrowa \& Howard, 1983; Odds, 1988) and clinical isolates are often variable in their response to inducive conditions. For example, proline is a strong inducer of germ tubes, yet in one study the percentage germination, among 15 randomly selected isolates in the presence of proline, ranged from 16-86\% (Dabrowa et al., 1976). In the present study the percentage of the spontaneous morphologic mutants $(\mathrm{m} 1-\mathrm{m} 20)$ that germinated in the presence of serum varied from $27-91 \%$. These recorded variations are associated with altered electrokaryotypes as is colonial morphology, but there is neither an obvious alliance of a given karyotype with a certain percentage germination (McEachern \& Hicks, 1991), nor with a certain type of colonial appearance.

Stable non-germinative isolates whose inability to germinate is not related to the methods employed are fairly uncommon, but have been consistently recorded in the literature (Torosantucci \& Cassone, 1983). The frequency of occurrence in one instance was $1-2 \%$ (Buckley et al., 1982), a frequency of the same order as that for spontaneous colony form mutants $(1.4 \%$; Rustchenko-Bulgac et al., 1990). We believe that in recording the frequency of a given phenotype, one ought to be particular about the parental strain used to obtain the variant. For example, the frequency of recovery of spontaneous mutants from an unstable variant of a clinical isolate can be expected to be much higher, generally speaking, than from the more stable 3153A. Also, the frequency can probably vary from experiment to experiment because of the fact that the strain which is studied is a changing mixture of different phenotypes and 
electrokaryotypes of the cells in the population. Indeed, 300 -SG was observed in one instance among $10^{3}$ cells of the same parental strain, 300, which, in the laboratory of H. Buckley, produced spontaneous non-germinative mutants with 10-times higher frequency (see above). Interestingly filamentation of a different type, namely pseudohyphae formation, was a very stable feature observed in all of the parental strains and the various mutants derived from them.

A study of the pigmentation and colonial morphology that resulted from cultivation of strains on bismuth sulphite- and Phloxine B-containing media uncovered an overwhelming amount of variability among the strains (Table 3). The growth of the strains at different temperatures revealed that all clinical isolates grew well within a broad range of temperatures and that nine of the spontaneous morphological mutants and the spontaneous non-germinative mutants, 301,302 and 303, also grew over a broad range of temperatures (Table 4, Groups $\mathrm{C}$ and $\mathrm{A}$, respectively). However, 10 of the spontaneous morphological mutants and the NTGinduced non-germinative $307 \mathrm{D}$ did not grow at $45^{\circ} \mathrm{C}$ and grew poorly at 16 and $40^{\circ} \mathrm{C}$. Induced mutants 311 and 312 , which were remarkable for the diversity of their populations of cells as manifested in mixed colonial forms (Fig. 5, Table 2) and collective electrophoretic karyotypes (Figs 2 and 3), grew consistently in sectors and papillae. Moreover, the range of temperature for growth of strains 311 and 312 was much narrower and strain 312 grew better at room temperature $\left(22^{\circ} \mathrm{C}\right)$ than at $37^{\circ} \mathrm{C}$, optimal for C. albicans.

In contrast to the experiments discussed above, the tests for chlamydospore formation and auxotrophy did not show appreciable variability. All four non-germinative mutants $(302,307 \mathrm{D}, 311$ and 312$)$ that originally formed chlamydospores lost this ability during laboratory maintenance. Only the UV-induced mutant, 312 , revealed any induced auxotrophic requirements. In addition, approximately 80 spontaneous colony morphology mutants checked recently were all prototrophic (Rustchenko-Bulgac, unpublished data). It appears that spontaneous mutations in chlamydospore production and auxotrophic requirements are rare events, despite multiple chromosomal alterations.

The many different combinations of colonial morphologies, textures and colours observed, as well as other highly variable features exceed the number of changes in karyotype among the strains. It is also important to note that these types of variability were not associated with a given karyotype. For example, chromosome III, which is frequently altered (Rustchenko-Bulgac, 1991, and Fig. 3 ), was nevertheless represented by co-migrating homologues in similar positions amongst non-related strains 300-SG, 307 and 310 and their progeny. However, a feature which was similar for all of them was not seen. There was no specific change common to all of the altered banding patterns that could be related to the inability to germinate (McEachern \& Hicks, 1991), nor was the pattern of spontaneous compared to induced non-germinative karyotypes distinctive. In previous work we probed the spontaneously altered chromosomal patterns with gene $A D E 2$ and observed that the Candida genome can undergo more changes than reflected by electrophoretic karyotype (Rustchenko-Bulgac et al., 1990). The inconsistency between phenotypic and chromosomal variability presented here provides additional support to this observation.

Finally, we wish to conclude that multiple new phenotypes among the spontaneous mutants of $C$. albicans cannot be explained solely through chromosomal aberrations detectable by electrophoretic karyotyping, despite the fact that the phenotypic variation and chromosomal changes occurred in the same population of cells.

The work was supported by US Public Health Service Grants AI25213 (D. H.H.), AI16252 (D.H.H.) and AI29433 (Fred Sherman) from the National Institutes of Health. We thank H. Kolbel for technical assistance. We gratefully acknowledge the assistance of $\mathrm{Dr} J$. Hicks who prepared the Southern blot hybridization used to establish the relatedness of mutants to their putative parents. We warmly thank F. Sherman for reading this manuscript.

\section{References}

Asakura, K., Iwaguchi, S.-I., Homma, M., Sukai, T., Higashide, K. \& TANAKA, K. (1991). Electrophoretic karyotypes of clinically isolated yeasts of Candida albicans and C. glabrata. Journal of General Microbiology 137, 2531-2538.

BRown-Thompsen, J. (1968). Variability in Candida albicans (Robin) Berkhout I. Studies on morphology and biochemical activity. Hereditas 60, 355-398.

BuCKLey, H. R., Price, M. P. \& DANeO-Moore, L. (1982). Isolation of a variant of Candida albicans. Infection and Immunity 37, 1209-1217.

CANNON, R. R. (1986). Isolation of a mycelial mutant of Candida albicans. Journal of General Microbiology 132, 2405-2407.

CARLE, G. F. \& Olson, M. V. (1984). Separation of chromosomal DNA molecules from yeast by orthogonal-field alternation gel electrophoresis. Nucleic Acid Research 12, 5647-5664.

COOPER, B. H. \& Silva-Hutner, M. (1985). Yeast of medical importance. In Manual of Clinical Microbiology, pp. 526-541. Edited by E. H. Lennette, A. Balows, W. J. Hausler, JR \& H. J. Shadomy. Washington, DC: American Society for Microbiology.

Cutler, J. E. (1991). Putative virulence factors of Candida albicans. Annual Review of Microbiology 45, 187-218.

DABROWA, N. \& HowARD, D. H. (1983). Blastoconidium germination. In Fungi Pathogenic for Humans and Animals, Part A: Biology, pp. 525-545. Edited by D. H. Howard. New York: Marcel Dekker.

Dabrowa, N., TAXER, S. S. \& Howard, D. H. (1976). Germination of Candida albicans induced by proline. Infection and Immunity 13, 830-835.

Dabrowa, N., Zeuthen, M. L. \& Howard, D. H. (1990a). Nutritional stress proteins in Candida albicans. Journal of General Microbiology 136, 1387-1391.

Dabrowa, N., Rustchenko-Bulgac, E. P., Hicks, J. B. \& Howard, D. H. (1990b). Karyotype variations among morphological mutants of Candida albicans. In Abstracts of the 3rd Symposium, Topics in 
Mycology, Mycoses in AIDS Patients, 1989, P. 13, p. 147. Janssen Pharmaceutica.

Edwards, J. E., Jr, Montgomery, J. Z., Ishada, K., Morrison, J. O. \& GuZE, B. (1975). Experimental hermatogenous endophthalmitis due to Candida: species variation in ocular pathogenicity. Journal of Infectious Diseases 135, 294-297.

Howard, D. H. \& Dabrowa, N. (1979). Mutants of Arthroderma benhamiae. Sabouraudia 17, 35-50.

Howard, D. H., Zeuthen, M. L. \& Dabrowa, N. (1986). Phenotypic characteristics of a slow-growing, non-germinative variant of Candida albicans. Journal of General Microbiology 132, 2359-2366.

IWAGUCHI, S.-I., Homma, M. \& TANAKA, K. (1992). Clonal variation in chromosome size derived from the rDNA cluster region in Candida albicans. Journal of General Microbiology 138, 1177-1184.

MCEACHERN, M. J. \& Hicks, J. B. (1991). Dosage of the smallest chromosome affects both the yeast-hyphal transition and the white-opaque transition of WO-1. Journal of Bacteriology 173, 7436-7442.

Maniatis, T., Fritsch, E. F. \& SAMBrooK, J. (1982). Molecular Cloning: A Laboratory Manual. Cold Spring Harbor, NY: Cold Spring Harbor Laboratory Press.

Mattia, E., Carruba, G., Angiolella, L. \& Cassone, A. (1982). Induction of germ tube formation by $N$-acetyl-D-glucosamine in Candida albicans: uptake of inducer and germinative response. Journal of Bacteriology 142, 555-562.

Merz, W. G. (1990). Candida albicans strain delineation. Clinical Microbiology Reviews 3, 321-334.

Merz, W. G., Connelly, C. \& Heiter, P. (1988). Variation of electrophoretic karyotypes among clinical isolates of Candida albicans. Journal of Clinical Microbiology 26, 842-845.

Meyer, S. A., Ahearn, D. G. \& Yarrow, D. (1984). Genus 4. Candida Berkout. In The Yeasts, A Taxonomic Study, pp. 585-844. Edited by N. J. W. Kregar-van Rij. Amsterdam: Elsevier.

Oblack, D., Schwarz, J. \& Holder, I. A. (1978). Biochemical examination of sera during systemic Candida infection in mice. Infection and Immunity 19, 992-998.

Oblack, D., Schwarz, J. \& Holder, I. A. (1980). In vivo muscle damage during Candida infection. Sabouraudia 18, 21-31.
ODDs, F. C. (1988). Candida and Candidosis. London: Balliere Tindall. OlaiYA, A., Steed, J. \& Sogin, S. (1980). Deoxyribonucleic aciddeficient strains of Candida albicans. Journal of Bacteriology 141, $1284-1290$.

Rustchenko-BulgaC, E. P. (1991). Variations of Candida albicans electrophoretic karyotypes. Journal of Bacteriology 173, 6586-6596.

Rustchenko-Bulgac, E. P., Sherman, F. \& Hicks, J. B. (1990). Chromosomal rearrangements associated with morphological mutants provide a means for genetic variation of Candida albicans. Journal of Bacteriology 172, 1276-1283.

Sadhu, S., McEachern, M. J., Rustchenko-Bulgac, E. P., Schmid, J., SolL, D. R. \& Hicks, J. B. (1991). Telomeric and dispersed repeat sequences in Candida yeasts and their use in strain identification. Journal of Bacteriology 173, 842-850.

Sherman, F., Fink, G. R. \& Hicks, J. B. (1986). Laboratory Course Manual for Yeast Genetics and Molecular Biology. Cold Spring Harbor, NY: Cold Spring Harbor Laboratory Press.

Slutsky, B., BufFo, J. \& Soll, D. R. (1985). High frequency switching of colony morphology in Candida albicans. Science 230, 666-669.

Slutsky, B., Staebell, M., Pfaller, M. \& Soll, D. R. (1987). The 'White-opaque transition': a second switching system in Candida albicans. Journal of Bacteriology 169, 189-197.

SOll, D. R., ANDERson, J. \& Bergen, M. (1991). The developmental biology of the white-opaque transition in Candida albicans. In Candida albicans, Cellular and Molecular Biology, pp. 20-45. Edited by R. Prasad. Berlin: Springer-Verlag.

Suzuki, T., Kobayashi, I., Kanbe, T. \& Tanaka, K. (1989). High frequency variation in colony morphology and chromosome reorganization in the pathogenic yeast Candida albicans. Journal of General Microbiology 135, 425-434.

Szaniszlo, P. J., Jacobs, C. W. \& Geis, P. A. (1983). Dimorphism: morphological and biochemical aspects. In Fungi Pathogenic for Humans and Animals, Part A : Biology, pp. 323-436. Edited by D. H. Howard. New York: Marcel Dekker.

TOROSANTUCCI, A. \& CASSONE, A. (1983). Induction and morphogenesis of chlamydospores in an agerminative variant of Candida albicans. Sabouraudia 21, 49-57.

Wickes, B. L., Golin, J. E. \& Kwon-Chung, K. J. (1991). Chromosomal rearrangement in Candida stellatoidea results in a positive effect on phenotype. Infection and Immunity 59, 1762-1771. 